\title{
Research on the Teaching of Comparative Literature
}

\author{
Hou Ying \\ School of Liberal Arts, Zhengzhou Normal University, Zhengzhou, 450044, China \\ houyin69@163.com
}

Keywords: Comparative Literature Course; the Teaching of the Comparative Literature

\begin{abstract}
College students generally welcome the comparative literature course, because it gives them an eye-opening experience and widens their scope of knowledge. After studying Chinese literature and foreign literature, they naturally wanted to learn from a new perspective and a new level of scrutiny. Learning comparative literature can meet their requirements and help them to look around the world. It makes them more concern about the direction of the development of literature and culture, in order to establish a new kind of humanism spirit and improve their sense of responsibility. Comparative literature is also a practical discipline. Learning comparative literature must be practiced and mastered in practice. Therefore, comparative literature teaching often includes theory, paradigm (examples and models), and practice. Combining these three aspects properly and making them cooperate with each other and promote each other is a good way to achieve good teaching results.
\end{abstract}

\section{Introduction}

Professor Yue Daiyun of Peking University, a famous comparative literature expert, in her lecture on "looking ahead to the Comparative Literature in the 21st Century" said: "comparative literature is not only a very important subject in the 21st century, but also a principle of life, a life attitude. It is a 'high-level research' and 'elite cultural', and should be a new humanistic spirit which is pervasive in most people. It helps to expand people's spiritual world and better understand themselves”.(1) As a Comparative literature course in humanities, it contains many disciplines which has a comparative, leaping and open nature. It provides students with a new learning platform, helps them to connect Chinese literature knowledge system which has been learned. Moreover, it offers students a new literary perspective, let them study literature starting from a new point of view. It can also build up literature and other social disciplines, which is a bridge between science and expand knowledge horizons of students.

\section{The significance of comparative literature courses in undergraduate colleges and Universities}

From 1978, Professor Shi Zhecun of East China Normal University set up comparative literature lectures, so far, comparative literature in college curriculum has been 38 years. In the process of all-round development of comparative literature, the teaching of comparative literature has gone through from nothing to perfection. From the perspective of the long-term development of disciplines, comparative literature has made gratifying achievements. First of all, comparative literature has been out of the situation which is been neglected of the country's education system and it takes its legal place in the national education system. That is to say, our teaching has entered the institu-tionalization process. Secondly, we began to establish a multi-level and complete teaching system of comparative literature from the general education to postgraduate education. With these two points, our comparative literature teaching has a long-term development of the premise and foundation. More than 30 years ago, because the comparative literature does not enter the national education system, the teaching of comparative literature is still in a spontaneous state. Its teaching is basically individual behavior of the school and teachers rather than the national regulations. They have car-ried out the course in some schools as that the college presidents and 
teachers attach importance to the course, but if no one advocates, then no one thinks it. Fortunately, comparative literature was officially included in the catalogue of postgraduate education in 1990 . Since then, comparative lit-erature has formally entered the educational system and academic system of the state. However, the course of comparative literature mainly teaches and researches in the Chinese Department, foreign language institutions and Foreign Language Department are not rarely carry out the teaching of the course. While the subject catalog can directly be put as a foreign language and literature of the two disciplines, the directory of the comparative literature teaching does not seem to have any effect. the Ministry of Education separated the comparative literature from the Chinese literature, and combined comparative literature with world literature as "two disciplines" in 1997. At present, compared with the requirements of the development of the discipline, the teaching of comparative litera-ture appears to be lagging behind. People don't know how to locate the comparative literature course of Liberal Arts in undergraduate teaching program. Subsequently, the Higher Education De-partment of the Ministry of Education issued the "undergraduate professional directory and profes-sional introduction" in 1998, which ranked "comparative literature and world literature" as one of the major courses in Chinese Language and Literature. At the same time, the Ministry of Education Division has put comparative literature into the curriculum of continuing education for "primary and secondary school teachers courses.” The comparative literature was paid attention to by Ministry of Education in China, so it became the main disciplines from the neglected position which compara-tive literature teaching was spontaneous, dispensable in the past.

The comparative literature and the world literature history of two independent disciplines, they can not replace each other. When comparative literature and world literature merges into one major, the postgraduate students in this field should become "a profession, two subjects" of the professionals, therefor the training objectives are different from the original single literature. In addition, they should also reflect the differences in the professional directions which postgraduates can major in comparative literature or world literature. In addition, they should also reflect the differences in the professional directions, which can be the main attack of comparative literature, or the main attack on world literature. In order for students to have two aspects of knowledge and ability, we can set the comparative literature theory, the world literature history and other courses as a common professional basic course. In order to show the differences of the professional directions, we should set up another professional courses. The comparative literature major can set up the history of comparative literature, comparative poetics, the history of the relationship between Chinese and foreign literature, the selection of comparative literature classics and other courses. The world literature major can set up a class of courses such as the research of classical writers, the modern literature, the history of literary criticism. We have both the commonality of the professions and the direction of the subjects as far as possible. "The teaching of comparative literature in our country has formed a complete system, which includes three levels: professional teaching, namely to cultivate specialized personnel of postgraduate teaching and comparative literature department; the other is universal teaching, that is undergraduate teaching, including basic and elective courses; and the last but not the least is enlightening teaching which the comparative literature concept and method applied to the Chinese teaching at the middle school.”(2)

In the past, we mainly opened comparative literature electives in universities at Chinese departments or the whole school. Such comparative literature course which has generally three types: the first type is a comprehensive teaching of basic principles of comparative literature with the name Introduction to Comparative Literature, Introduction to Comparative Literature, Comparative Literature Theory, etc. The second type is to teach one aspect of the system of comparative literature, such as comparative poetics, history of Chinese and foreign literature, literature and religion, literature and art, mythology and literature, etc. And the third kind is to combine the comparative literature with other subjects, such as Western Modernism and Chinese Modern Literature, Comparative Study of Chinese and Western Literature Type, etc. The comparative literature elective course offered by teachers' personal behavior is somewhat arbitrary and is impossible to unify the requirements. When comparative literature is institutionalized and its 
own teaching system is formed and when comparative literature becomes a required course for undergraduate courses, we can not stay in such a spontaneous and disorderly state. For example, we must consider what objectives should be achieved in the teaching of comparative literature in university and how does it work with graduate students and how to distinguish them, that is, the different teaching objectives and teaching contents should be taken into consideration at all levels of the teaching system. Many people believe that undergraduate teaching is limited by training goals, teaching plans, teaching hours and so on. The requirements of comparative literature teaching must be moderate, and they can not be asked as required by postgraduate students in comparative literature. The teaching of comparative literature for undergraduates can only be made through the study of Chinese literature and foreign literature. For example, there is no need to set up a comprehensive and systematic course of The Introduction of Comparative Literature. It is worth considering whether the school knowledge of comparative literature and the history of the comparative literature can not be talked about, how much the basic principles of the subject will be said and so on. In a word, how to make the undergraduate course suitable for the undergraduate course and make our undergraduate course teaching some basis, we should also have a comparative literature syllabus applicable for the undergraduate course, and with practical teaching reference materials at the same time.

At present, the another big problem faced by undergraduate comparative literature teaching is how to deal with the relationship between comparative literature and world literature after the decision of subject merger. These are two different disciplines, so it is not advisable to abolish foreign literature courses and replace them with the comparative literature. However, whether the subject merger also has brought a new idea to our curriculum reform: the combination of the new curriculum. Take foreign literature as an example. The foreign literature of a course is not a random list of the world's literature, but it is carded into a complete system under the guidance of certain concept. It is inevitable to apply the ideas and methods of comparative literature to the foreign literature, otherwise it will be impossible to examine their relationship and identify their contribution to the development of world literature. The decision of disciplines merging requires us to consciously use the ideas and methods of comparative literature to promote the teaching reform of foreign literature.

Besides learning the history of foreign literature, college students need to learn some basic theories of comparative literature. How can we teach this course well? Concentrating on one point is the combination of theory and practice. As a subject, comparative literature has formed a set of theoretical systems of its own. However, if teaching is in the theory, it is inevitable that a vivid course will be insipid and uninteresting. The value of the idea and method of comparative literature is that it opens up the neglected world in the past and solves the problem that cannot be solved. The new academic field, new research subjects, new perspectives and new methods are the specialties of this subject. Many teachers' comparative literature classes have been welcomed by students. The important reason is that they can give full play to the director of the subject, and use a large number of examples and models to fully display these new worlds, new ideas and new achievements, and then give a theoretical explanation. Comparative literature is also a practical discipline. Learning comparative literature must be practiced and mastered in practice. Therefore, comparative literature teaching often includes theory, paradigm (examples and models), and practice. Combining these three aspects properly and making them cooperate with each other and promote each other is a good way to achieve good teaching results. A large number of examples and models to arouse the students' interest in learning; the guidance and sublimation of the theory leads them bring to the best; and then through practical operations, let them experience the mysteries of them personally. In conclusion, it is important to pay special attention to the teaching should pay special attention to the importance of practice in undergraduate teaching, so that the comparative literature should not be referred to as "metaphysics". It is worth noticing that in recent years, comparative literature has the tendency of theorization and pan-culture. The problems discussed in academic circles and some articles are too abstract and vague. We do not have to put the metaphysical discussion on the platform in undergraduate teaching in order to avoid teaching abstract theory and lose the charm of 
comparative literature.

\section{The teaching orientation should be clearly defined, and the subject concept of comparative literature should be adapted to the talent training target of education.}

Compared with the requirement of discipline development and talent cultivation at present, comparative literature teaching is lagging behind. Some scholars have classified undergraduate teaching as the basic teaching stage of the three level teaching system of undergraduate, master and doctor. However, the goal setting and value orientation of the basic teaching of comparative literature has not been clearly elucidated. On the other hand, the positioning of undergraduate teaching of comparative literature in Chinese undergraduate curriculum system is rather vague. In 1997, the Ministry of education separated the comparative literature from Chinese literature and merged it into "two level disciplines". In the teaching practice of many colleges and universities, the course of comparative literature and the history of world literature are taught respectively. There are many differences in the understanding of the teaching of Comparative Literature: the comparative literature teaching is the supporting teaching of the course of world literature history, or is the same position as the world literature history teaching in the sense of "the two level subject". The link between Comparative literature teaching and other subjects in Chinese teaching. At present, the situation of comparative literature course in universities is different. Many teachers are puzzled about teaching objectives, contents and methods. The author believes that the concept of comparative literature determines the close relationship between the teaching of comparative literature and the teaching of foreign literature, and plays the role of integrating the knowledge of other courses in Chinese undergraduate courses and improving the students' humanistic quality.

The comparative literature breaks through the boundaries of space and region, the division of subject's category and the estrangement of the cultural subject. In the open field of view, it seeks the factual and aesthetic relations between literary phenomena and the cross relationship between literary phenomena and other subjects, explores the essence of literature, and forms the "cross-cultural and interdisciplinary literature". Wang Li said: "The teaching and research of comparative literature should strengthen first-level discipline consciousness and break the methodology of 'the assemblage of writers and writings' in the teaching of literary history by producing stimulating projects and ideas.” (3)The information and network of contemporary culture expands the boundaries of various disciplines and promotes interdisciplinary interdisciplinary. The pattern of multiculturalism in the world is recognized in the context of globalization, and the connection between literature and culture has become an inevitable trend. The discipline concept of comparative literature has rich connotations in the new cultural context. From the view of culture, comparative literature regards world culture as a combination of multiculturalism, which has to emphasize that different cultures can bring people the enlightenment of understanding themselves and the world, and respect the existence of each culture and the right to speak. On one hand, comparative literature can advocate an open and inclusive cultural vision of the world which objectively and dialectically treats and evaluates the status of literary phenomena in the history of the development of human culture. On the other hand, it can advocate that people enhance mutual understanding between different cultures, and dispel the subjective prejudices of ethnic, racial and ideological aspects. In terms of literature, comparative literature asserts that it should be liberated from the traditional literary concepts and methods of literature, that is to say, it should surpass the barriers of culture, discipline, language and method, and should use comparative methods to open up research fields and extension research levels around the relationship between literature and culture.

The discipline concept of comparative literature is the guiding ideology of undergraduate teaching in comparative literature, which is consistent with the goal of talent training in Chinese undergraduate education. According to talent standards in our country, Chinese undergraduate students must have a perfect quality structure, including the knowledge structure which contains solid knowledge and extensive knowledge of other subjects, ability structure which consists of learning ability, innovation ability, practical ability, language ability, communication ability and 
social application ability, and the structure of the literacy which includes humanities accomplishment, moral qualities, ideological and political literacy. The undergraduate teaching of comparative literature will help to form the students' cross-cultural vision, improve their creative thinking, comprehensive ability and humanistic spirit, and cultivate the students' cultural consciousness and enterprising spirit in the context of globalization, so that they can grow into the construction of national culture, the transmission of human civilization, the casting of the spirit of the times, and the participation in the international dialogue of the students in the future.

\section{Reasonable arrangement of teaching contents, and the connection between academic resources of comparative literature and the knowledge structure of students.}

The comparative literature course is highly specialized and has a large capacity, but the class hour which contains thirty-two to thirty-six sessions of the comparative literature course at the undergraduate level is short. "It is an important task for scholars to change the teaching status of this course. The key to solve this problem is to give the undergraduate comparative literature teaching in a clear position, distinguish it from the graduate teaching, and build the actual teaching system suitable for undergraduates." (4)Whether the undergraduate teaching of comparative literature can attract students depends on reasonable teaching design and rich and vivid teaching contents. Because the comparative literature discipline is more theoretical, it is easy to make the theoretical coloring of comparative literature in undergraduate teaching is too strong. In my opinion, the main reason for this situation is that the academic attainment of teachers is not yet harmoniously connected with the students' knowledge basement. The course of comparative literature is generally opened for senior students. At this stage, students are still in the basic stage of knowledge, but they have learned the history of Chinese literature, the history of Chinese and foreign literature theory and the study of literature and art, which have a certain demand for the depth and breadth of comparative literature teaching. Teachers should start from the knowledge structure and interests of the students at the undergraduate level, absorb the students' resources of comparative literature according to their academic level and the students' acceptance and knowledge needs, and take the needs of the discipline construction as the main purpose and the academic hot spot as the guide, take the problem consciousness as the outline, and enrich the dialogue spirit. Taking literary imagination as an example, we combine theoretical exploration with phenomenon research to guide students' effective learning.

In accordance with the above principles, teachers can properly compress the two chapters of "the history and present situation of comparative literature" and " the research methods of comparative literature". In the course of teaching, we can highlight the openness and foresight of comparative literature. At present, the academic circles of comparative literature in China advocate "cross-cultural research and inter-cultural dialogue", and propose equal dialogue with the world comparative literature. From this academic hot point, we can discuss the development of comparative literature from two aspects: vertical aspect and horizontal aspect. In the longitudinal way, the comparative literature teaching can contribution to the theory of Chinese comparative literature, and let the students understand the intercultural dialogue proposed by Chinese comparative literature is a new research method developed on the basis of the study of the influence of the French school and the parallel study of the American school. Teachers can compare and contrast the knowledge base, cultural background, research field and characteristics of the three methods, so that students can clearly grasp the overall context of the development of the theory of comparative literature. On the horizontal side, teachers can put Chinese comparative literature in the contemporary cultural context, and explore the cultural responsibility consciousness of Chinese comparative literature against cultural hegemonism and denial of cultural isolationism in the pluralistic pattern from the world cultural situation.

\section{Acknowledgements}

To sum up, the establishment of the comparative literature course is imminent, and it can be 
applied to the needs of cultivating innovative talents with wide caliber, thick foundation, strong ability and all-round quality in the contemporary society. The teaching of comparative literature can give full play to the advantages of the subject and the distinctive features of the curriculum. The teachers of the Chinese department should renew the teaching content and improve the teaching methods with the times, cultivate the students' habit of comparative thinking, get through the barriers, and integrate the literary phenomena of ancient and modern.

\section{References}

[1] Yue Daiyun in her lecture on "looking ahead to the Comparative Literature in the 21st Century", Superstar academic video, http://video.chaoxing.com/play_400001104_17003.shtml.

[2] Chun Chen, Review and Reflection on Comparative Literature Teaching, China Comparative Literature, the fourth issue in 2005, total sixty-first issue, twenty-first pages.

[3] Wang Li, Ponder on the relationship between comparative literature and Chinese literature history, The first issue of Chinese comparative literature in 2014, total ninety-fourth issue, 183rd pages.

[4] Jiang Fang, Clear positioning: the top priority of undergraduate Comparative Literature Teaching, the fourth issue of China Comparative Literature in 2005, total sixty-first issues, thirty-third pages. 